\title{
Prenatal Tanımlanmış Kritik Valvüler Aort Darlığı
}

\author{
Bedri Aldudak', Mekki Bilici², Osman Akdeniz1, Muhittin Çelik ${ }^{3}$
}

\begin{abstract}
ÖZET:
Prenatal tanımlanmış kritik valvüler aort darlığı

Amaç: Kritik valvüler aort darlığı en sık fetal kardiyak girişim gerektiren doğumsal kalp hastalığıdır. Bu olgu, ülkemizde fetal kardiyak cerrahinin önemine vurgu yapmak amacı ile sunulmuştur.

Olgu: Olgumuz 18 yaşındaki annenin ilk gebeliğinden 29. Gestasyonel haftada 1600 gram doğan kız bebek. Prenatal 24. Gestasyonel haftada kritik valvüler aortik stenoz saptanıp doğumda resüsite edilip entübe edildi. Akciğer grafisinde ağır respiratuar distres sendromu bulguları olması üzerine solunum destek cihazına bağlanarak iki doz sürfaktan verildi. Dopamin ve alprostadil infüzyonu başlandı. Postnatal ekokardiyografik incelemede sol ventrikül yetmezliğinin eşlik ettiği kritik aort darlığı tanısı teyid edildi. Postnatal 5. saatte balon aortik valvüloplasti işlemi yapıldı. Yaşamsal bulgularında kısmi düzelme gözlenen hasta işlemden sonraki 4. saate yoğun bakımda kaybedildi.

Sonuç: Ülkemizde fetal kardiyak girişimlerin yapılabileceği merkez sayısının yeterli düzeye çıkarılması gerektiği kanısındayız.
\end{abstract}

Anahtar kelimeler: İnutero girişim, kritik valvüler aort darlı̆̆ı, mortalite

\section{ABSTRACT:}

Prenatally diagnosed critical valvular aortic stenosis

Objective: Critical valvular aortic stenosis is the most common congenital heart disease which requires fetal cardiac intervention. This case is presented to emphasize the significance of prenatal intervention in our country.

Case: Our case is a female infant with a birthweight of $1600 \mathrm{~g}$ at $29^{\text {th }}$ gestational weeks from the first pregnancy of an 18 years old mother. At prenatal $24^{\text {th }}$ gestational weeks critical valvuler aortic stenosis detected and resuscitated and entubated at birth. At chest roentgenogram there was findings of respiratory distress syndrome, so mechanical ventilation support applied and 2 doses of surfactant therapy given. Dopamine and alprostadil infusion was started. Critical aortic stenosis diagnosis with accompanying left ventricular failure was confirmed following postnatal echocardiographic examination. Aortic valvuloplasty preocedure was applied at the postnatal fifth hour. The patient observed to have partial improvement in vital findings following balloon valvuloplasty but was lost four hours after the intervention.

Conclusion: We believe that the number of centers where cardiac interventions will implent must be increase to a satisfactory level.

Key words: Inutero intervention, critical valvular aortic stenosis, mortality

Ş.E.E.A.H. Tıp Bülteni 2015;49(3):218-20
'Diyarbakır Çocuk Hastanesi, Pediatrik Kardiyoloji Kliniği, Diyarbakır-Türkiye ${ }^{2}$ Dicle Üniversitesi, Tıp Fakültesi, Pediatrik Kardiyoloji Anabilim Dalı, Diyarbakır-Türkiye ${ }^{3}$ Diyarbakır Çocuk Hastanesi, Neonatoloji Kliniği, Diyarbakır-Türkiye

Yazışma Adresi / Address reprint requests to: Muhittin Çelik,

Diyarbakır Çocuk Hastalıkları Hastanesi,

Pediatri Bölümü, Yenidoğan Kliniği,

Yenişehir Mahallesi Hasteneler Caddesi, 21100

Diyarbakır-Türkiye

Telefon / Phone: +90-533-680-7376

Faks / Fax: +90-412-229-0147

E-posta / E-mail:

mehdincelik@hotmail.com

Geliş tarihi / Date of receipt: 22 Temmuz 2014 / July 22, 2014

Kabul tarihi / Date of acceptance: 27 Ağustos 2014 / August 27, 2014

\section{GíRiş}

Valvüler aort darlığı doğumsal kalp hastalıklarının \%3-6'sını oluşturur (1). Klinik seyir darlığın derecesi ile ilişkilidir. Kritik aort darlığı durumunda rahim içinde ölüm ve hidrops gelişebileceği iyi bilinmekte- dir (2). Bu durum ayrıca hipoplastik sol kalp sendromu gelişiminde de etkilidir (2). Kritik aort darlı̆̆ı prenatal dönemde güvenilir bir şekilde tanımlanabilmekle birlikte doğru erken cerrahi grişim uygulanmadığı durumlarda postnatal tedavi mortalitesi yüksektir (3). Prenatal dönemde inutero aortik valvüloplastinin 
postnatal süreç üzerine pozitif katkısına inanılmaktadır (2). Bilinen ilk fetal aortik valvülaplasti 1989 yılında yapılmıştır (4-5). Türkiye'de bizim bildiğimiz ilk vaka Gül ve ark'na ait olup 28. gebelik haftasında valvüloplasti uygulanmış ancak olgu kaybedilmiştir (2).

\section{OLGU}

Onsekiz yaşında anne, hamileliğinin 24. haftasında yapılan fetal ekokardiyografide fetusta kritik aort darlığı saptandı. Prenatal ekokardiyografi; sol kalp dilate, LVEDd $1.4 \mathrm{~cm}$. kalp fonksiyonları azalmış, EF \%39, ağır mitral yetmezlik mevcut. Aort kapak hareketleri kısıtlı, aortik anülüs $3 \mathrm{~mm}$. Aort kapak düzeyinde akım hızı $2 \mathrm{~m} / \mathrm{sn}$. Asendan aorta çapı $6 \mathrm{~mm}$. Aort kavisi normal, pulmoner venler dilate idi (Resim 1). Olguya fetal kardiyak girişim (aortik valvüloplasti) düşünüldü ancak işlemin yapılabileceği bir merkez bulunamadı. Olgu 29. gestasyonel haftada spontan olarak vajinal yolla doğdu. Apgar skoru 1 ve 5 . dakikada sırası ile 3 ve 2 olarak değerlendirildi. Fizik muayenesinde: $1600 \mathrm{~g}$ ağırlığında, genel durumu kötü, spontan solunumu yok \%100 oksijenle oksijen saturasyonu \%70, nabız 126/dk, tansiyon arteriyel alınamıyordu. Olguya doğduğunda canlandırma işlemi uygulanarak entübe edildi. Solunum destek cihazına bağlanarak ilk tetkikleri yapıldı. Akciğer grafisi (yaygın retikülogranüler patern ile havalanma kaybına bağlı akciğerlerde dansite artışı) ağır respiratuar distres sendromu ile uyumluydu, kapiller kan gazı ise $\mathrm{pH}$ : 6.83, $\mathrm{pCO}_{2}$ : 144, $\mathrm{pO}_{2} .17, \mathrm{HCO}_{3}$ : 22.3,

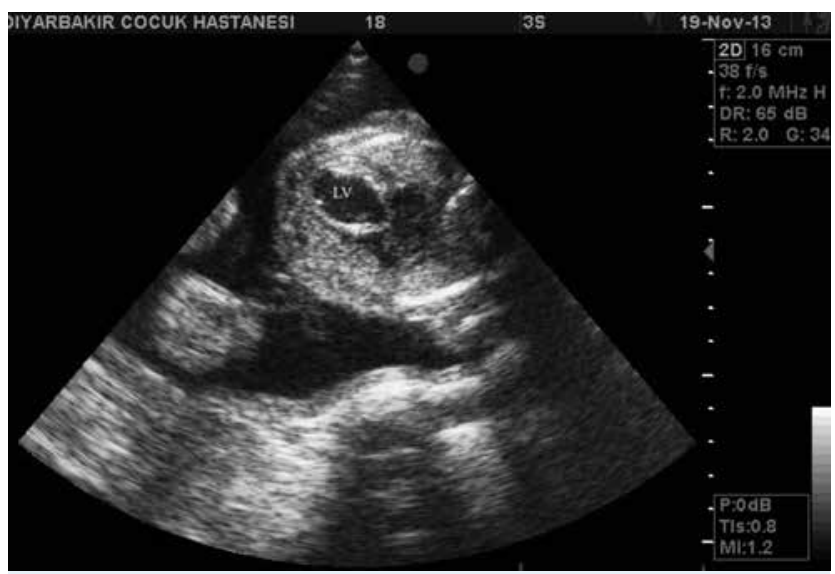

Resim 1: Dilate sol ventrikül
BE.-17.5 idi. Olguya iki doz sürfaktan verildi ve kardiyoloji kliniği ile konsülte edildi. Postnatal ekokardiyografi; sol atriyum geniş, sol ventrikül EF \%45, orta derecede mitral yetmezlik mevcuttu. Mitral kapak kısıtlı açılıyordu, aortik anülüs 4,4 mm, aort kapak hareketleri kısıtlı idi. Asendan aortada minimal antegrad akım saptandı, akım hızı $2.3 \mathrm{~m} / \mathrm{sn}$ idi ve hafif aort yetmezliği izlendi. Bu bulgular ile olguda kritik valvüler aort darlığı teyid edildi ve buna bağlı sol kalp yetmezliği geliştiği düşünüldü. Dopamin $(10 \mu \mathrm{gr} / \mathrm{kg} /$ $\mathrm{dk}$ ), alprostadil $(0.01 \mu \mathrm{gr} / \mathrm{kg} / \mathrm{dk}$ ) ve furosemid (1 mg/ $\mathrm{kg}$ ) başlanarak aortik balon valvüloplasti için tersiyer merkeze sevk edildi.

Postnatal 5. saatte hasta kateter odasına alındı. Kateter esnasında aort anülüsü $4.5 \mathrm{~mm}$ olarak ölçüldü. Aort kapak hareketlerinin ileri derecede kısıtlı olduğu ancak sol ventrikül ve aort arasında basınç farkı olmadığı görüldü. 4×15 ve 5×15 mm koroner balon ile valvüloplasti işlemi yapıldı. İşlemden sonra sistemik kan basıncı 50/20 mm Hg, oksijen satürasyonu \%100, kalp hızı 104/dk olan hasta entübe şekilde yenidoğan yoğun bakım ünitesine pediatrik kardiyolog refakatinde transfer edildi. Girişim sonrası olgunun hayati fonksiyonlarda kısmi iyileşme saptanmasına rağmen 4 saat sonra kaybedildi.

\section{TARTIŞMA}

Kritik aort stenozu postnatal mortalitesi yüksek bir hastalıktır (3). Postnatal uygulanan cerrahi tedavinin sonuçları sol ventrikül çapına ve sol ventrikülün preoperatif kondisyonuna bağlıdır. Kritik aort stenozu ile doğan bebeklerde sol ventrikül çıkım yolu darlığı ve sol ventrikül disfonksiyonu nedeniyle oluşan düşük kardiyak debi, ağır metabolik asidoza ve ağır genel durum bozukluğuna yol açmaktadır. Kritik aort darlığı hastalarında mortalite \%30-50 arasındadır. Erken tanı ve uygun koşullarda doğum ile mortalite \%20 civarına çekilebilmektedir (6). Doğumdan sonra sol ventrikül çıkım yolu darlığı giderilmiş olsa bile sıklıkla sol ventrikül yeterli kardiyak outputu sağlayamamaktadır (2). Midgestasyonel dönemde tanı konan hastalarda inutero ölüm, hipoplastik sol kalp sendromuna gidiş, sol ventrikül disfonksiyonuna bağlı hidrops fetalis ve endokardiyal fibroelastozis geliştiği görülmüştür $(2,7)$. Sol ventrikülün bulunduğu olum- 
suz durumdan erken kurtarılmasının postnatal sonuçlar üzerine olumlu etki sağlayacağı ileri sürülmektedir (2). Bu nedenle bir çok merkez midgestasyonel dönemde tanı alan kritik aort stenozlu olgularda inutero aortik valvüloplastiyi alternatif bir tedavi yöntemi olarak kullanmaktadır $(3,7)$.

Bizim olgumuzda ilk tanı 24. gestasyonel haftada kondu. Sol ventrikül dilatasyonu ve ağır mitral yetmezlik ile birlikte ejeksiyon fraksiyonu \%39 idi. Pulmoner venler belirgin genişlemişti. Tanı aldıktan 5 hafta sonra olgu ikinci düzey bir hastanede doğdu. Derin ve miks tipte asidozu mevcuttu. Postnatal ekokardiyografi prenatal tanının devamı şeklindeydi. Sol kalp yetmezliği yanı sıra ağır respiratuvar distress sendromu bulguları mevcuttu. Respiratuvar distress sendromunun ağırlığı prematüritenin yanı sıra muhtemelen ağır pulmoner venöz staz ile de ilişkiliydi. Hastanın genel durum stabilizasyonuna yönelik ted- birleri alındıktan sonra postnatal 5. saatte aortik valvüloplasti yapıldı. Ancak hasta kısa bir süre sonra yoğun bakımda kaybedildi. Hastada literatür verileri ile birebir uyumlu bir süreç gözlendi. Bu hastada prenatal tanı aldıktan sonra inutero aortik valvüloplasti ile sürecin olumlu yönde seyrinin değiştirilebileceği yargısı devam etmektedir.

\section{SONUÇ}

Kritik valvüler aortik darlık fetal kardiyak girişimin en sık uygulandığı doğumsal kalp hastalığıdır. Girişim postnatal süreci ciddi olarak etkilemektedir. Ülkemizde henüz yeterli deneyime sahip bir merkez bulunmaması nedeniyle bu hasta grubuna zamanında tedavi hizmeti sunulamamaktadır. Bu vaka üzerinden ülkemizin önemli açıklarından birine değinmek istiyoruz.

\section{KAYNAKLAR}

1. Freed MD. Aortic stenosis. In: Allen HD, Gutgesell HP, Clark EB, et al. (eds). Moss and Adams' Heart Disease in Infants, Children, and Adolescents. $6^{\text {th }}$ ed. Philadelphia: Lippincott Williams \& Wilkins; 2001.p.970-88.

2. Gül A, Saygılı A, Kavuncuoğlu S, Ceylan Y. Fetusta kritik aort darlı̆̆ı için balon valvuloplasti: Olgu sunumu Türk Kardiyol Dern Arş 2013; 41: 161-5.

3. Simpson JM, Sharland GK. Natural history and outcome of aortic stenosis diagnosed prenatally. Heart 1997; 77: 205-10.

4. McElhinney DB, Tworetzky W, Lock JE. Current Status of Fetal Cardiac Intervention. Circulation 2010; 121: 1256-63.

5. Maxwell D, Allan L, Tynan MJ. Balloon dilation of the aortic valve in the fetus: a report of two cases. Br Heart J 1991; 65: 2568.

6. Huhta JC, Carpenter RJ Jr, Moise KJ Jr, Deter RL, Ott DA, McNamara DG. Prenatal diagnosis and postnatal management of critical aortic stenosis. Circulation 1987; 75: 573-6.

7. Mäkikalli K, McElhinney DB, Levine JC, Marx GR, Colan SD, Marshall AC, et al. Fetal Aortic Valve Stenosis and the Evolution of Hypoplastic Left Heart Syndrome, Patient Selection for Fetal Intervention. Circulation 2006; 113: 1401-5. 